\title{
Trends of cardiothoracic trauma at new trauma centre
}

\author{
P Mhandu*, S Chaubby, D Robb, M Uzzaman, H Khan, D Whitaker \\ From 23rd World Congress of the World Society of Cardio-Thoracic Surgeons \\ Split, Croatia. 12-15 September 2013
}

\section{Background}

To analyse the demographics, types and mechanisms of injury, management and outcomes of all cardiothoracic trauma during the first year of a South London Major Trauma Centre in comparison to national standards.

\section{Methods}

A retrospective analysis of a trauma database in conjunction with electronic patient records and paper notes for the 12 month period April 2010 to March 2011.

\section{Results}

Of 1556 trauma patients, 254 had cardiothoracic trauma. $90 \%(228 / 254)$ were male and $10 \%(26 / 254)$ were female. Median age of all patients was 26 (range 1-91). 57\% (145) were penetrating injuries mainly knife wounds (128) and gunshots (10). 43\% (109) were blunt injuries (90 high and 19 low velocity). The actual injuries are detailed with rib fractures $(35 \%)$ and pneumothorax $(30 \%)$ the commonest and cardiac (5\%) and diaphragm (3\%) injuries the least common. $48 \%$ (121) of all cases had isolated thoracic injury, with $52 \%$ (133) being multiply injured. Of those multiply injured $36 \%$ (48) had head injuries, $65 \%$ (87) had orthopaedic injuries and 32\% (43) had abdominal injuries. Operative and non-operative management is described in detail. Of the 15 patients requiring cardiothoracic surgery, 6 had a clamshell incision, 5 posterolateral thoracotomy, 2 median sternotomy and 1 thoracoscopy. Overall mortality was $3.5 \%$ (9/254). Operative mortality was $13 \%(2 / 15)$. Median length of stay was 4 days.

\section{Conclusion}

Despite a higher incidence of violent penetrating trauma compared to the national average of $2 \%$ of all thoracic trauma, the pre hospital care and in hospital multi-

\footnotetext{
* Correspondence: pmhandu@icloud.com Kings College Hospital, London, UK
}

(C) 2013 Mhandu et al; licensee BioMed Central Ltd. This is an Open Access article distributed under the terms of the Creative Commons Attribution License (http://creativecommons.org/licenses/by/2.0), which permits unrestricted use, distribution, and reproduction in any medium, provided the original work is properly cited. disclipinary approach with resident cardiothoracic care results in a favourably low mortality.

Published: 11 September 2013

\section{doi:10.1186/1749-8090-8-S1-074}

Cite this article as: Mhandu et al.: Trends of cardiothoracic trauma at new trauma centre. Journal of Cardiothoracic Surgery 2013 8(Suppl 1):074. and take full advantage of:

- Convenient online submission

- Thorough peer review

- No space constraints or color figure charges

- Immediate publication on acceptance

- Inclusion in PubMed, CAS, Scopus and Google Scholar

- Research which is freely available for redistribution 